\title{
Circulating miRNAs Associated with Dysregulated Vascular and Trophoblast Function as Target-Based Diagnostic Biomarkers for Preeclampsia
}

\author{
Suji Kim ${ }^{1,+}{ }^{+}$Minsik Park ${ }^{1,{ }^{\dagger}}$, Ji-Yoon Kim ${ }^{2,+}{ }^{\oplus}$, Taesam Kim ${ }^{1,+}{ }^{\dagger}$ Jong Yun Hwang ${ }^{3}$, \\ Kwon-Soo Ha ${ }^{1}$, Moo-Ho Won ${ }^{4}{ }^{\mathbb{D}}$, Sungwoo Ryoo ${ }^{5}$, Young-Guen Kwon ${ }^{6}$ and \\ Young-Myeong $\mathrm{Kim}^{1, *(\mathrm{D})}$ \\ 1 Departments of Molecular and Cellular Biochemistry, School of Medicine, Kangwon National University, \\ Chuncheon, Gangwon-do 24341, Korea; tnw10210@naver.com (S.K.); whitealstlr@naver.com (M.P.); \\ tskim0602@naver.com (T.K.); ksha@kangwon.ac.kr (K.-S.H.) \\ 2 Department of Anesthesiology and Pain Medicine, Hanyang University Hospital, Seoul 04763, Korea; \\ irisjy00@hanmail.net \\ 3 Departments of Obstetrics and Gynecology, School of Medicine, Kangwon National University, Chuncheon, \\ Gangwon-do 24341, Korea; rapidhwang@kangwon.ac.kr \\ 4 Departments of Neurobiology, School of Medicine, Kangwon National University, Chuncheon, \\ Gangwon-do 24341, Korea; mhwon@kangwon.ac.kr \\ 5 Department of Life Sciences, College of Natural Sciences, Kangwon National University, Chuncheon, \\ Gangwon-do 24341, Korea; ryoosw08@kangwon.ac.kr \\ 6 Department of Biochemistry, College of Science and Biotechnology, Yonsei University, Seoul 03722, Korea; \\ ygkwon@yonsei.ac.kr \\ * Correspondence: ymkim@kangwon.ac.kr; Tel.: +82-33-250-8831; Fax: +82-33-244-3286 \\ + These authors contributed equally to this work.
}

Received: 6 July 2020; Accepted: 29 August 2020; Published: 31 August 2020

check for updates

\begin{abstract}
Preeclampsia (PE) is a pregnancy-specific disorder associated with hypertension and proteinuria. Since there is no proven method to treat $\mathrm{PE}$, early prediction and accurate diagnosis are essential for appropriate management of the disease. Thus, reliable biomarkers for diagnosing PE need to be identified and evaluated. We analyzed serum-soluble factors and miRNAs in 92 patients with PE and an equal number of healthy controls to identify new useful biomarkers for PE. Serum miR-31-5p, miR-155-5p, and miR-214-3p levels were significantly elevated in these patients and highly correlated with clinical symptoms of hypertension and proteinuria, whereas the miR-1290-3p level was decreased. The increased miRNAs were upregulated in an NF-кB-dependent manner and suppressed endothelial nitric oxide synthase (eNOS) and placental growth factor (PlGF) expression. The level of each miRNA had greater than $90 \%$ diagnostic accuracy, which was further increased by analyzing its ratio relative to that of miR-1290-3p. Taken together, the ratios of miR-31-5p, miR-155-5p, or miR-214-3p to miR-1290-3p may serve as reliable diagnostic or prognostic tools for PE, thereby providing evidence that these miRNAs are promising mechanism-based targets for designing therapeutic and preventive strategies for the clinical management of PE.
\end{abstract}

Keywords: preeclampsia; miRNA; diagnostic biomarker; vascular dysfunction

\section{Introduction}

Preeclampsia (PE), a pregnancy-specific disease associated with hypertension, proteinuria, thrombocytopenia, or renal insufficiency, is a common disorder affecting $5 \%$ to $7 \%$ of all pregnancies [1]. It is a major cause of maternal mortality (10-15\%) worldwide and accounts for a substantial proportion of low-birth-weight neonates and iatrogenic preterm delivery [2,3]. 
The incidence of PE has persistently increased in the past decade due to an increase in the prevalence of predisposing factors, such as maternal age, chronic hypertension, diabetes, renal disease, and obesity [3]. Although the pathogenesis of PE is still enigmatic, increasing evidence reveals that inadequate placentation due to the deficient trophoblastic invasion of the uterine spiral arteries elicits placental hypoxia, immune activation and proinflammatory cytokine production, decreased levels of angiogenic factors, and increased levels of antiangiogenic factors, resulting in the acceleration of the clinical symptoms of PE [4]. Much research into the pathogenesis and mechanism of PE has been conducted; however, its occurrence, development, and morbidity have remained unchanged over the past decade. Therefore, a precise diagnosis using accurate biomarkers associated with pathogenesis is needed to enable the best possible management and treatment of PE.

PE has been clinically diagnosed in pregnant women with elevated blood pressure $(\geq 140 / 90 \mathrm{mmHg})$ and urinary protein excretion $(>300 \mathrm{mg} / 24 \mathrm{~h})$ after 20 weeks of gestation, but these are both secondary features of a primary placental problem and subject to measurement error and poor test accuracy [5]. Therefore, the identification of accurate biomarkers to enable the prognosis of preeclamptic complications could substantially contribute to management strategies, with the aim of minimizing adverse maternal and fetal outcomes. A growing body of studies has demonstrated that PE is highly associated with increased levels of antiangiogenic factors, such as soluble fms-like tyrosine kinase 1 (sFlt-1) and soluble endoglin (sEng), and decreased levels of angiogenic factors, including placental growth factor (PIGF) [5-8]. Based on this finding, a high sFlt-1/PIGF ratio has been indicated shortly before the onset of PE $[9,10]$. Therefore, these circulating factors have been recommended as diagnostic and prognostic biomarkers of PE. However, this antiangiogenic state does not always lead to clinical syndromes such as hypertension and proteinuria in patients with PE, although the reasons for this are still unclear [11,12]. Therefore, new specific biomarkers that can be directly linked to the pathogenesis of clinical features, diagnosis, and therapeutic strategies for PE still need to be discovered.

Major discoveries and rapid progress in miRNA research during the past few years have highlighted that the circulating levels of some specific miRNAs are elevated in many types of human diseases and might have great potential in the diagnosis and therapy of many diseases, including PE, in the near future [13-16]. Our recent studies demonstrated that miRNA (miR)-31-5p and miR-155-5p are detected at high levels in sera from patients with PE. These miRNAs elicit vascular dysfunction associated with hypertension and proteinuria through the impairment of the endothelial nitric oxide synthase/nitric oxide (eNOS/NO) and soluble guanylate cyclase/protein kinase G (sGC/PKG) pathways [15-19]. This suggests that PE-derived miRNAs associated with the impairment of vasorelaxation and vascular remodeling can be used as diagnostic and therapeutic biomarkers of PE. However, no diagnostic value analysis has been reported using miRNAs based on pathogenic mechanisms or symptoms of PE.

In this study, we identified several miRNAs, such as miR-31-5p, miR-155-5p, miR-214-3p, and miR-1290-3p, whose levels were significantly altered in sera from patients with PE. Their levels were highly correlated with clinical symptoms of PE and had high diagnostic accuracy and specificity for PE. Based on these data, we clearly defined their possible roles not only as useful diagnostic biomarkers for suspected PE but also in vascular dysfunction and the pathogenesis of the disease.

\section{Materials and Methods}

\subsection{Subjects}

Approval for the use of human subjects was obtained from the Institutional Review Board of Kangwon National University Hospital, South Korea (KNUH-2017-01-010-005), and informed consent was obtained from all the participants. This prospective case-control study included 92 women with $\mathrm{PE}$ and 92 normotensive pregnant women selected at random, who were enrolled in the Department of Obstetrics and Gynecology, Kangwon National University Hospital, between February 2017 and September 2019. Women with pre-existing diabetes mellitus, chronic hypertension, elevated liver 
enzyme levels, twin or multiple pregnancies, or any evidence of previous medical illness were excluded. PE was defined as systolic blood pressure $\geq 140 \mathrm{mmHg}$ and/or diastolic blood pressure $\geq 90 \mathrm{mmHg}$ on at least two occasions $4 \mathrm{~h}$ apart but no more than 7 days apart, which developed after 20 weeks of gestation in previously normotensive women; proteinuria was defined as $\geq 300 \mathrm{mg}$ protein in a $24 \mathrm{~h}$ urine specimen, as previously described [20]. No women with pre-existing hypertension, with or without superimposed PE, were included in the present study. All experiments were carried out in accordance with the approved guidelines and regulations, in line with the tenets of the Declaration of Helsinki.

\subsection{Sample Collection}

The serum fractions were obtained according to standard protocols from all participants. Briefly, at the time of clinic attendance, maternal venous blood samples were collected into standard Vacutainer tubes (EDTA, Becton-Dickinson, Franklin Lakes, NJ, USA) and processed within $1 \mathrm{~h}$ by centrifugation at $2000 \times g$ for $10 \mathrm{~min}$ at $4{ }^{\circ} \mathrm{C}$. The supernatants were quickly removed, aliquoted, and stored immediately at $-80{ }^{\circ} \mathrm{C}$. For analysis, serum samples were thawed on ice and centrifuged at $3000 \times g$ for $5 \mathrm{~min}$, avoiding traces of red blood cells and other cellular debris that could affect miRNA analysis. Placentas were also obtained after full-term normal (spontaneous vaginal) deliveries, and maternal arteries were isolated from the placental bed from the patients as described previously [15].

\subsection{Cell Culture and Treatment}

Human umbilical vein endothelial cells (HUVECs) were obtained from Cell Systems (Kirkland, WA, USA) and grown in complete media, as previously described [16]. Human trophoblast-derived HTR-8/SVneo cells were cultured in RPMI 1640 medium supplemented with 10\% fetal bovine serum. The human intestinal epithelial cell line DLD-1 was obtained from the American Type Tissue Collection and grown in Dulbecco modified Eagle's medium (DMEM) supplemented with 10\% fetal calf serum. The cells were transfected with $80 \mathrm{nM}$ of miScript Inhibitor Negative Control (\#1027271; Qiagen, Hilden, Germany), miR-31-5p inhibitor (\#MIN0000089; Qiagen, Hilden, Germany), miR-155-5p inhibitor (\#MIN0000646; Qiagen, Hilden, Germany), miR-214-3p inhibitor (\#MIN0000271; Qiagen, Hilden, Germany), or miR-1290-3p inhibitor (\#MIN0005880; Qiagen, Hilden, Germany) using Lipofectamine RNAiMAX (\#56532; Invitrogen, Carlsbad, CA, USA) as previously described [16]. HUVECs and HTR-8/SVneo cells were stimulated with tumor necrosis factor (TNF)- $\alpha$ (10 ng/mL, \#210-AT; R\&D Systems, Minneapolis, MN, USA) in the presence or absence of Bay 11-7092 (5 $\mu \mathrm{M}$, \#196870; Calbiochem, San Diego, CA, USA) for $24 \mathrm{~h}$, and DLD-1 cells were treated with a mixture of TNF- $\alpha$, interleukin (IL)- $1 \beta$ (20 ng/mL, \#201-LB; R\&D Systems, Minneapolis, MN, USA), and interferon (IFN)- $\gamma$ ( 20 ng/mL, \#285-IF; $\mathrm{R} \& \mathrm{D}$ Systems, Minneapolis, MN, USA) for $24 \mathrm{~h}$. These treatment conditions were used according to previous results to observe the optimal response of each cell type to the cytokines $[15,16,21]$.

\section{4. miRNA Isolation and Quantitative Reverse Transcription Polymerase Chain Reaction ( $q$ RT-PCR)}

RNA was isolated from serum $(200 \mu \mathrm{L})$ and cultured cells using the miRNeasy Mini Kit (\#217184; Qiagen, Hilden, Germany) according to the manufacturer's protocol and eluted with $14 \mu \mathrm{L}$ of nuclease-free water. cDNA for analyzing miRNAs was prepared from $1 \mu \mathrm{g}$ of total miRNA using a miScript II RT kit (\#218161; Qiagen, Hilden, Germany). qRT-PCR was performed with a miScript SYBR Green PCR kit (\#218073; Qiagen, Hilden, Germany) according to the manufacturer's instructions. The levels of miRNAs were analyzed by miScript Primer Assay with target miRNA-specific and universal primers. The relative levels of miRNAs were normalized to SNORD-95. In addition, total mRNA was isolated using TRIzol reagent (\#15596018, Invitrogen, Carlsbad, CA, USA) from cultured cells and placental tissues. mRNA levels of $e N O S$ in placental bed-derived arteries, inducible nitric oxide synthase (iNOS) in placental tissue, and glyceraldehyde-3-phosphate dehydrogenase (GAPDH) were determined by HiPi Real-Time PCR 2X Master Mix (SYBR Green, Elpis, Daejeon, Korea) with a Rotor-Gene Q real-time PCR cycler (Qiagen) using target-specific primers as previously described [15]. 
The primers used in this study are as follows: 5'-GTGGCTGTCTGCATGGACCT-3' (forward) and 5'-CCACGATGGTGACTTTGGCT-3' (reverse) for eNOS, 5'-TTCTTCGCCAGACCAAACTG-3' (forward) and $5^{\prime}$-GGAAGTAGGTGAGGGCTTGC-3' (reverse) for iNOS, and 5'-GGGGCTCTCCAGAACATCAT-3' (forward) and 5'-GGTCAGGTCCACCACTGACA-3' (reverse) for GAPDH.

\subsection{Measurement of sFlt-1, sEng, PlGF, Nitrite and Nitrate, and cGMP}

Serum levels of sFlt-1 (\#DVR100B), sEng (\#DNDG00), PlGF (\#DPG00), TNF- $\alpha$ (\#DTA00C), and cyclic guanosine monophosphate (cGMP; \#KGE003) were determined according to the manufacturer's protocol using ELISA kits (R\&D Systems, Minneapolis, MN, USA). Serum levels of NO production [NOx, nitrite $\left(\mathrm{NO}_{2}^{-}\right)+$nitrate $\left.\left(\mathrm{NO}_{3}{ }^{-}\right)\right]$were analyzed using a nitrate reductase-based nitric oxide assay kit (\#ab65328; Abcam, Cambridge, MA, USA).

\subsection{Western Blot Analysis}

Harvested cells were suspended in RIPA buffer [ $50 \mathrm{mM}$ Tris- $\mathrm{HCl}$, pH 8.0, $150 \mathrm{mM} \mathrm{NaCl}, 1 \%$ Nonidet P-40, 0.5\% deoxycholic acid, $0.1 \%$ sodium dodecyl sulphate (SDS)], and incubated on ice for $30 \mathrm{~min}$ for complete cell lysis. Cell debris was removed by centrifugation at $12,000 \times g$ for $15 \mathrm{~min}$. Lysates $(40 \mu \mathrm{g})$ were separated by SDS-polyacrylamide gel electrophoresis, and target protein levels were determined by Western blot analysis using antibodies for eNOS (\#610297; BD Biosciences, Franklin Lakes, NJ, USA) and iNOS (\#NB300-605; Novus Biologicals, CO, USA).

\subsection{Statistical Analysis}

Statistical analyses were undertaken using GraphPad Prism version 6.0 (GraphPad Software, San Diego, CA, USA). All clinical samples, except those for Western blotting, were analyzed in triplicate, and data are expressed as mean \pm SEM. Statistical significance was determined using Student's $t$-test between two groups, and the correlation between the two factors was determined by linear regression analysis. Receiver operating characteristic (ROC) curves were used to analyze the diagnostic utility of differentially expressed miRNAs or produced serum factors. The optimal cut-off point for the plasma miRNA expression level was determined by the Youden index $(\mathrm{J}=$ sensitivity + specificity -1$)$. Statistical significance was established at $p<0.05$.

\section{Results}

\subsection{Levels of sFlt-1, sEng, and PlGF in Sera from Patients with PE}

Clinical characteristics of the study participants are shown in Table 1. No significant difference in patient age was noted between healthy pregnant women and preeclamptic patients. However, preeclamptic participants had significantly increased blood pressure (systolic and diastolic, $115.20 \pm 0.84$ vs. $157.80 \pm 1.90 \mathrm{mmHg} ; 74.89 \pm 0.78$ vs. $99.85 \pm 1.20 \mathrm{mmHg}, p<0.001)$ and proteinuria $(1.89 \pm 0.19 \mathrm{~g} / 24 \mathrm{~h}, p<0.001)$. Moreover, these women delivered low-birth-weight fetuses $(3.08 \pm 0.06$ vs. $2.39 \pm 0.07 \mathrm{~kg}, p<0.001)$ approximately 1.8 weeks earlier $(p<0.001)$ than the healthy controls. On the basis of the relationship between gestational age and birth weight, the percentage of small for gestational age (SAG) infants (or intrauterine growth retardation; IUGR), appropriate for gestational age (AGA) infants, and large for gestational age (LGA) infants were $29.3 \%, 68.5 \%$, and $2.2 \%$, respectively, in the women with PE. AGA was defined as a birth weight between $10 \%$ and $90 \%$ of the average body weight in infants at the same gestational age, while LGA and SGA or IUGR were defined as a birth weight of more than $90 \%$ and less than $10 \%$ of the average body weight in infants at the same gestational age, respectively [22,23]. Maternal serum concentrations of the antiangiogenic factors sFlt- 1 and sEng were significantly higher $(p<0.001)$ in the preeclamptic patients than in the healthy subjects, whereas levels of the angiogenic factor PlGF were decreased in patient sera $(p<0.001$; Figure $1 \mathrm{~A}-\mathrm{C})$, consistent with previous reports $[6,24]$. As expected, the sFlt-1/PlGF ratio, known as a predictive marker of PE, 
was significantly higher in women with PE than in healthy subjects $(p<0.001)$ and showed a better predictive value than either biomarker alone (Figure 1D). This suggests that the pathological symptoms and analytical characteristics observed in the patients belonged to the typical PE spectrum.

Table 1. Clinical parameters of normal and preeclamptic pregnancies.

\begin{tabular}{cccc}
\hline Characteristics & $\begin{array}{c}\text { Healthy pregnancy } \\
(\boldsymbol{n}=\mathbf{9 2})\end{array}$ & $\begin{array}{c}\text { Preeclampsia } \\
(\boldsymbol{n}=\mathbf{9 2})\end{array}$ & $p$-Value \\
\hline Age at pregnancy (year) & $31.49 \pm 0.50$ & $32.73 \pm 0.54$ & 0.0946 \\
Gestational age at delivery (week) & $37.52 \pm 0.38$ & $35.72 \pm 0.28$ & 0.0002 \\
Systolic blood pressure (mmHg) & $115.20 \pm 0.84$ & $157.80 \pm 1.90$ & $<0.0001$ \\
Diastolic blood pressure $(\mathrm{mmHg})$ & $74.89 \pm 0.78$ & $99.85 \pm 1.20$ & $<0.0001$ \\
Urinary protein $(\mathrm{g} / 24 \mathrm{~h})$ & $\mathrm{N} / \mathrm{A}$ & $1.89 \pm 0.19$ & $\mathrm{~N} / \mathrm{A}$ \\
Birth weight $(\mathrm{kg})$ & $3.08 \pm 0.06$ & $2.39 \pm 0.07$ & $<0.0001$ \\
\hline
\end{tabular}

Values are presented as mean \pm SEM. N/A = not available, $n=92$ per group.
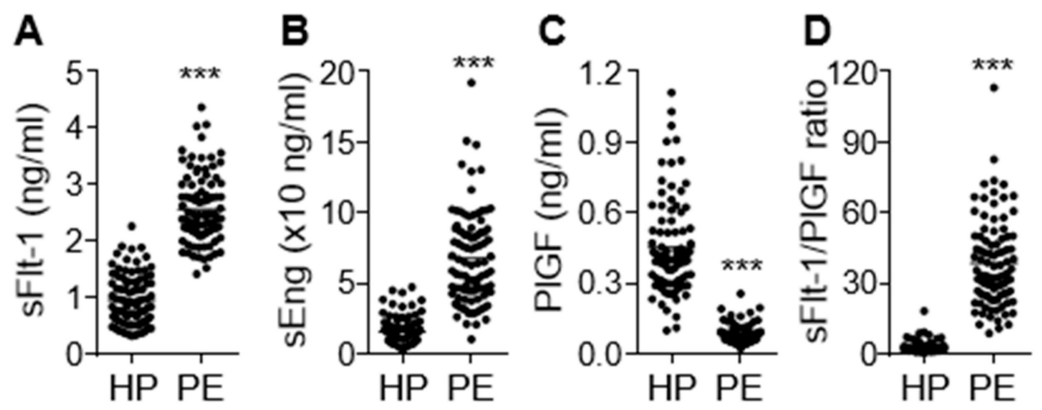

Figure 1. Serum levels of sEng, sFlt-1, and placental growth factor (PlGF) in healthy pregnant women (HP) and preeclampsia (PE) patients (PE). Serum levels of sFlt-1 (A), sEng (B), and PlGF (C) were measured using ELISA ( $n=92$ per group). (D) The ratio of sFlt-1 to PlGF. ${ }^{* *} p<0.001$.

\subsection{Comparative Levels of eNOS, iNOS, NO, cGMP, and TNF- $\alpha$ in PE Patients}

The NO/cGMP axis plays a crucial role in vascular relaxation, and impairment of the axis causes endothelial and vascular dysfunction, which are associated with vascular constriction and glomerular endotheliosis and result in hypertension and proteinuria [25]. We determined the levels of NO and cGMP in the sera of PE patients and control subjects. Unexpectedly, the levels of both molecules were significantly higher in PE patients compared to healthy control subjects (Figure 2A,B). The NOx levels were positively correlated with the cGMP levels (Figure 2C), indicating that the increased cGMP levels are derived by NO-dependent activation of sGC. Both NOx and cGMP levels also positively correlated with the serum sFlt-1/PIGF ratio, a suitable diagnostic marker of PE (Figure 2D,E), indicating that the elevated NO and cGMP levels might be serological features of PE. To investigate which isotype of NOS was responsible for the elevated serum NOx and cGMP levels in the patients, we examined the expression levels of $e N O S$ and $i N O S$ in umbilical cords and placental tissues immediately after delivery. In contrast to serum NOx and cGMP levels, eNOS mRNA levels were significantly decreased in maternal arteries of the placental bed from the PE patients (Figure 2F), whereas $i N O S$ expression was significantly increased in their placental tissues (Figure 2G). Furthermore, the elevated NOx levels in the patients were negatively correlated with $e N O S$ mRNA levels and positively correlated with $i N O S$ mRNA levels (Figure 2H,I), suggesting that the increased NO/cGMP levels in the patients might be derived from increased iNOS expression. Since inflammatory cytokines, including TNF- $\alpha$, stimulate the iNOS/NO/cGMP pathway [26] and inhibit the eNOS/NO/cGMP pathway [15-19], the relationship between serum levels of TNF- $\alpha$ and $e N O S$ or $i N O S$ expression was assessed. Our results showed that the serum TNF- $\alpha$ levels were significantly increased in PE patients (Figure 2J) and positively correlated with the sFlt1/PlGF ratio (Figure 2K). More notably, the serum TNF- $\alpha$ levels were inversely correlated with $e N O S$ mRNA levels and positively correlated with iNOS mRNA levels (Figure 2L,M), suggesting 
that TNF- $\alpha$ stimulated the iNOS/NO/cGMP pathway but inhibited the eNOS/NO/cGMP axis, probably by activating the transcription factor NF-KB $[17,26]$. Collectively, these data suggest that PE is likely to be associated with TNF- $\alpha$-mediated downregulation of eNOS, although total serum NO/cGMP levels are elevated through TNF- $\alpha$-induced induction of iNOS in preeclamptic patients.
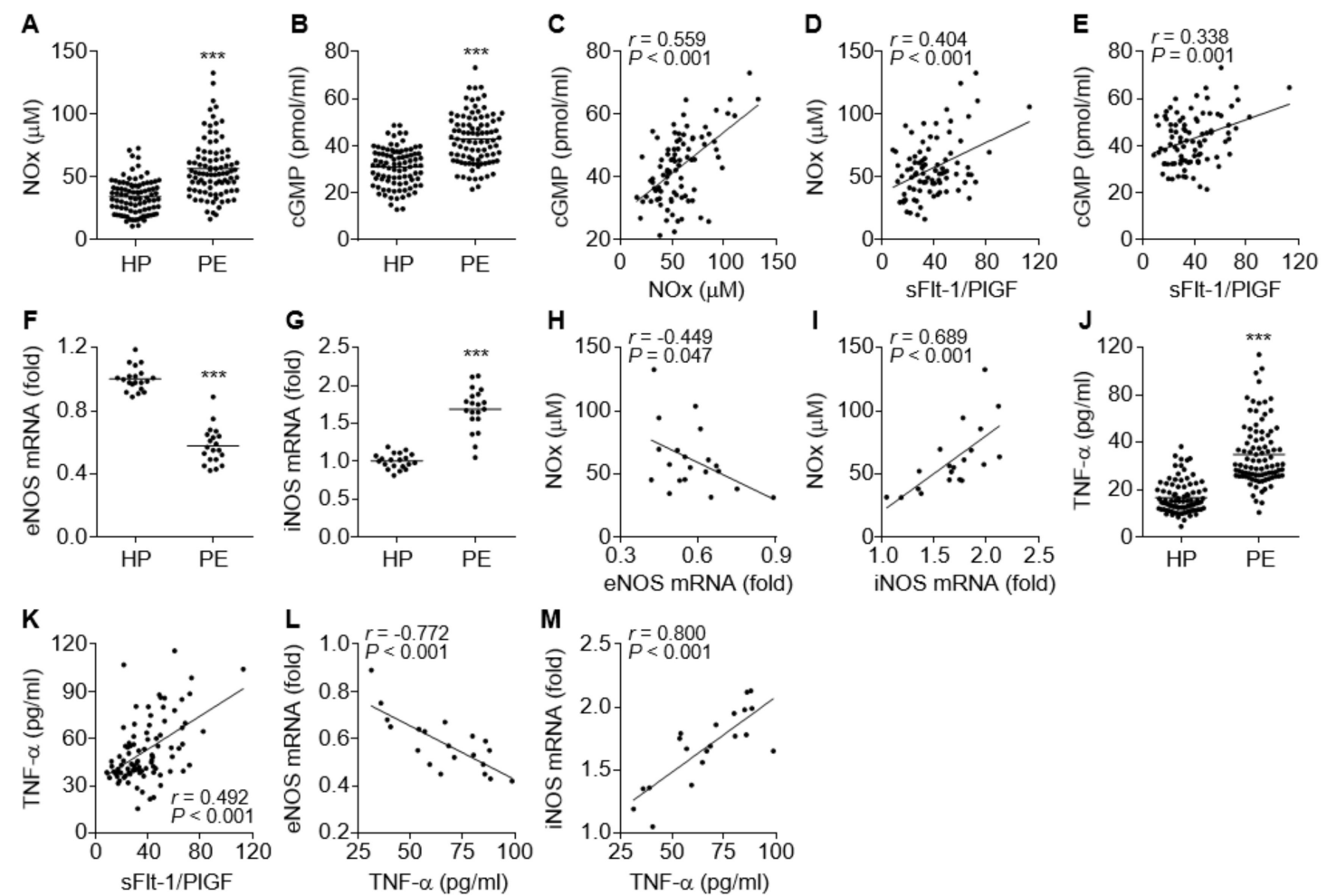

Figure 2. Comparative levels of endothelial nitric oxide synthase (eNOS), inducible nitric oxide synthase (iNOS), NOx, cGMP, and TNF- $\alpha$ in healthy pregnant women (HP) and PE patients (PE). (A,B) Levels of NOx (A) and cGMP (B) were measured using a nitrate reductase-based nitrated assay kit and an ELISA kit, respectively $(n=92)$. (C-E) Correlation analysis among the serum levels of NOx, cGMP, and the sFlt-1/PlGF ratio in PE patients $(n=92)$. $(\mathbf{F}, \mathbf{G})$ Expression levels of $e N O S(\mathbf{F})$ and $i$ NOS mRNAs $(\mathbf{G})$ were determined in placental tissues from healthy controls and PE patients $(n=20)$. (H,I) Correlation analysis between NOx level and eNOS $(\mathbf{H})$ or iNOS mRNA levels $(\mathbf{I})$ in PE patients $(n=20)$. (J) Levels of TNF- $\alpha$ were measured in sera from healthy subjects and PE patients by ELISA $(n=92)$. (K-M) Correlation analysis between TNF- $\alpha$ levels and the sFlt-1/PlGF ratios $(K, n=92)$, as well as between TNF- $\alpha$ levels and $e N O S(\mathbf{L}, n=20)$ or $i N O S$ mRNA levels $(\mathbf{M}, n=20)$, in PE patients. ${ }^{* * *} p<0.001$.

\subsection{Identification of miRNAs that are Positively and Negatively Regulated in PE Patients}

Inflammation-dependent and NF-kB-responsive miR-31-5p and miR-155-5p have been shown to impair endothelial and vascular function via the downregulation of eNOS, sGC, and PKG in the vasculature [16-19]. Circulating levels of both miRNAs were significantly elevated in PE patients compared to healthy controls (Figure 3A,B), consistent with previous reports [15,16]. Since miR-214 and miR-1290 have been shown to be positively and negatively regulated by hypoxia and estrogen, respectively, which are responsible for the pathogenesis of PE [4,27], we examined the alteration of their expression levels in the sera from patients with PE. The circulating miR-214-3p levels were also increased in the patients (Figure 3C), whereas miR-1290-3p was downregulated (Figure 3D). Notably, miR-31-5p, miR-155-5p, and miR-214-3p levels were highly correlated not only with TNF- $\alpha$ levels but also with the sFlt-1/PlGF ratio of these patients (Figure 3E-G,I-K), whereas miR-1290-3p levels were negatively correlated with TNF- $\alpha$ levels and the sFlt-1/PlGF ratio in the patients (Figure 3H,L). Collectively, these data suggest that increased serum levels of miR-31-5p, miR-155-5p, and miR-214-3p 
and decreased serum levels of miR-1290-3p are useful biomarkers for the pathogenesis and prognosis of PE.
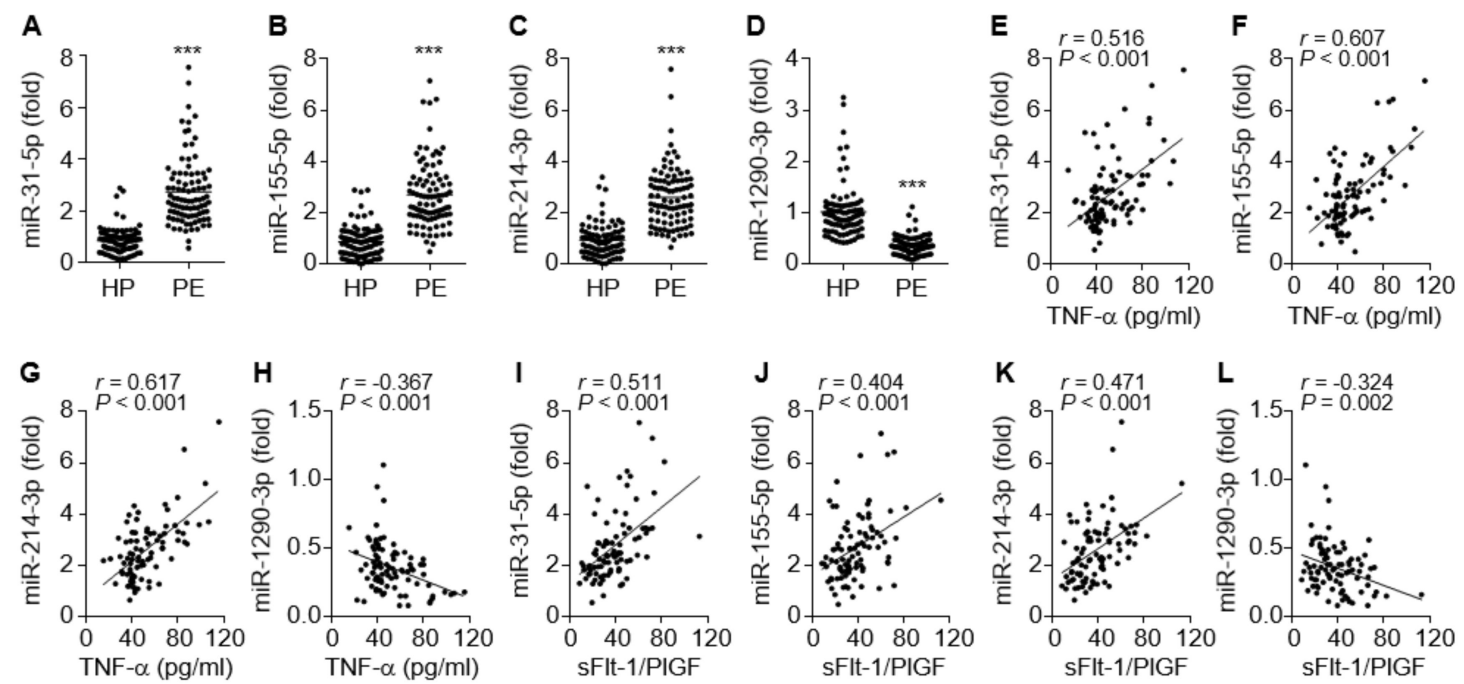

Figure 3. Serum levels of miRNAs in healthy pregnant women (HP) and PE patients (PE), and the correlation between miRNA levels and TNF- $\alpha$ or the sFlt-1/PlGF ratio. (A-D) Levels of miR-31-5p (A) and miR-155-5p (B), miR-214-3p (C), and miR-1290-3p (D) were measured in sera from healthy subjects and PE patients by qRT-PCR. (E-H) Correlation analysis between TNF- $\alpha$ levels and miRNA levels. (I-L) Correlation analysis between the sFlt-1/PlGF ratio and the level of each miRNA. $n=92$ per group. *** $p<0.001$.

\subsection{Correlation between the miRNAs and the NOS/NO/cGMP Axis or PIGF Level in PE Patients}

We next investigated which miRNA is possibly involved in the regulation of the eNOS- or iNOS-dependent NO/cGMP pathway in patients with PE. Circulating levels of miR-31-5p, miR-155-5p, and miR-214-3p were inversely correlated with eNOS mRNA levels (Figure 4A-C) and positively associated with the levels of iNOS expression, NOx production, or cGMP synthesis (Figure 4E-G, I-K, and $\mathrm{M}-\mathrm{O}$ ). By contrast, circulating miR-1290-3p levels were partially correlated with the eNOS mRNA level and negatively associated with the levels of iNOS mRNA, NOx, and cGMP (Figure 4D, H, L, and P). Because miR-214-3p has been shown to target PlGF transcripts, we examined the correlation of miR-214-3p and PIGF levels in the sera of PE patients. Serum levels of miR-214-3p were inversely correlated with PIGF levels (Figure 4Q). These data suggest that all four miRNA levels are positively or inversely correlated with the levels of eNOS, iNOS, NO/cGMP, and PIGF in PE patients. 

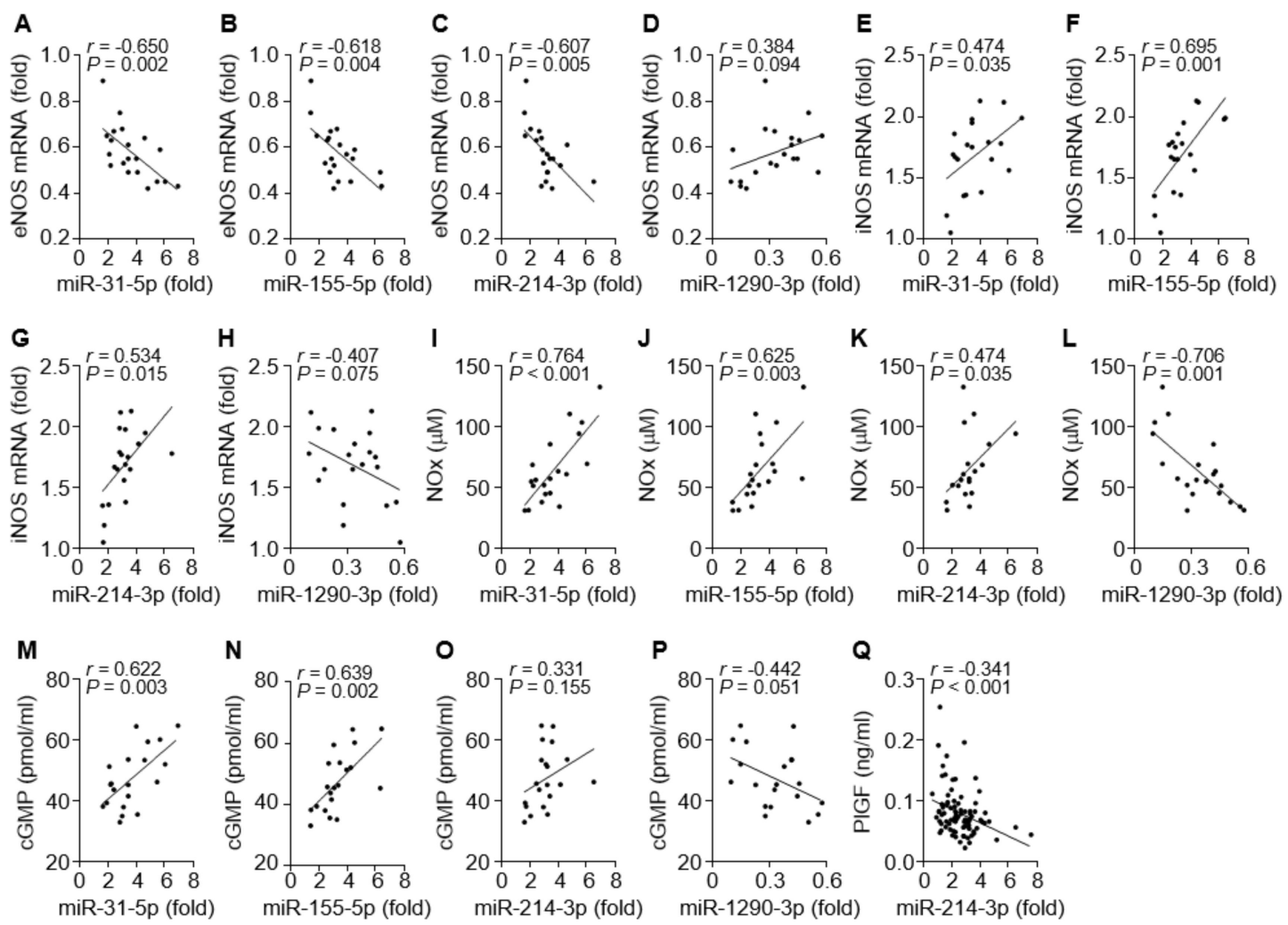

Figure 4. Correlation among eNOS mRNA, iNOS mRNA, NOx, cGMP, and miRNAs in tissues and sera from PE patients. (A-D) Correlation analysis between eNOS mRNA and miR-31-5p (A), miR-155-5p (B), miR-214-3p (C), or miR-1290-3p level (D). (E-H) Correlation analysis between iNOS mRNA and the level of each miRNA. (I-L) Correlation analysis between NOx level and the level of each miRNA. (M-P) Correlation analysis between cGMP level and the level of each miRNA. (Q) Correlation analysis between PIGF and miR-1290-3p levels. $n=20$ in A-P and $n=92$ in (Q).

\subsection{The miRNAs Differentially Regulate iNOS, eNOS, and PlGF Expression}

Since increased cytokine levels in PE patients dysregulate vascular function and trophoblast activity via regulation of the NOS/NO pathway and PlGF production $[15,28]$, we further investigated which miRNA is responsible for the regulation of eNOS, iNOS, and PIGF expression in cell culture systems. Treatment of HUVECs with TNF- $\alpha$ resulted in significant increases in the biogenesis of miR-31-5p, 155-5p, and miR-214-3p, but not of miR-1290-3p, which were abolished by the NF-kB inhibitor Bay 11-7082 (Figure 5A). Similar results were observed in HTR-8/SVneo cells and DLD-1 cells treated with TNF- $\alpha$ alone or in combination with IL-1 $\beta$ and IFN- $\gamma$, respectively, in the presence or absence of Bay 11-7082 (Figure 5B,C), suggesting that miR-31-5p, 155-5p, and miR-214-3p, but not miR-1290-3p, are expressed in an NF-kB-dependent manner. As shown in our previous reports [16,17], TNF- $\alpha$ suppressed eNOS expression in HUVECs, and this suppression was rescued by cotreatment with Bay 11-7802 or transfection with an inhibitor of miR-31-5p or miR-155-5p, but not of miR-214-3p and miR-1290-3p (Figure 5D). TNF- $\alpha$ treatment suppressed PIGF production in HTR-8/SVneo cells, which were recovered by treatment with Bay 11-7082 or transfection with miR-214-3p inhibitor, but not with other miRNA inhibitors (Figure 5E). Meanwhile, immune-activated DLD-1 cells induced iNOS expression, which was blocked by treatment with Bay 11-7082, but not by transfection with miRNA inhibitors (Figure 5F). These data indicate that iNOS, eNOS, and PlGF expressions are differentially regulated in the clinical conditions of PE via NF- $\mathrm{KB}$ activation, which plays a crucial role in iNOS expression, miR-31-5p/155-5p-mediated eNOS downregulation, and miR-214-3p-mediated PlGF suppression (Figure 5G). 
A

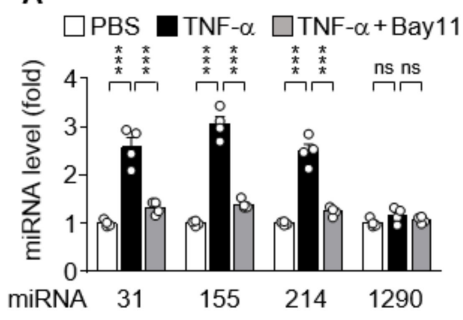

B

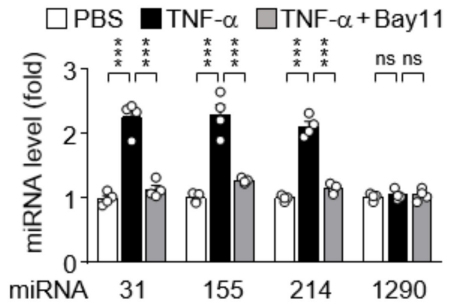

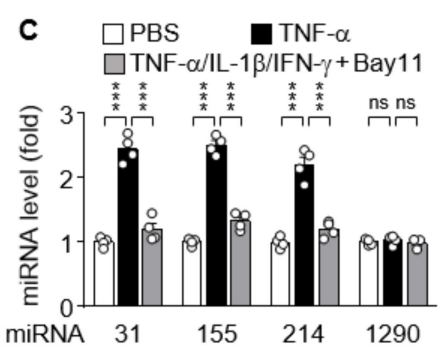

G

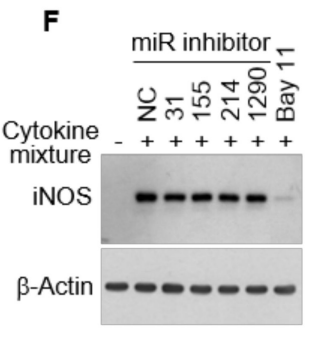

Inflammation

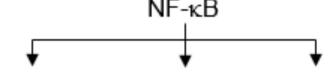

$\uparrow \mathrm{miR}-31-5 \mathrm{p} \uparrow \mathrm{miR}-214-3 \mathrm{p} \quad \uparrow \mathrm{iNOS}$ $\uparrow \mathrm{miR}-155-5 p$

$\downarrow$ ENOS/NO $\quad \downarrow$ PIGF $\quad \uparrow N O$

Figure 5. Functional role of cytokine-mediated NF- $\mathrm{kB}$ activation in miRNA biogenesis and expression of other genes. (A-C) HUVECs (A), HTR-8/SVneo cells (B), and DLD-1 cells (C) were treated with TNF- $\alpha$ or TNF- $\alpha /$ IL-1 $\beta /$ IFN- $\gamma$ in the presence or absence of Bay 11-7082 (Bay11) for $24 \mathrm{~h}$. Levels of the miRNAs were quantified by qRT-PCR $(n=4)$. (D-F) Cells were transfected with negative control (NC) or miRNA inhibitor, followed by treatment as above. The expression levels of eNOS, PIGF, and iNOS were determined in HUVECs (D), HTR-8/SVneo cells (E, $n=4)$, and DLD-1 cells (F), respectively, by Western blotting and ELISA. (G) Schematic diagram depicting the roles of inflammation-associated NF- $\kappa B$ activation in eNOS, PlGF, and iNOS expression. ns, not significant. ${ }^{* * *} p<0.001$.

\subsection{TNF- $\alpha$ and the miRNAs are Associated with Clinical Symptoms of PE}

To evaluate the possible links between the circulating miRNA levels and clinical symptoms, such as hypertension and proteinuria, in PE patients, we compared the relationship between them. Systolic blood pressure of the patients was evidently correlated with levels of TNF- $\alpha(r=0.445$, $p<0.001)$, miR-31-5p $(r=0.557, p<0.001)$, miR-155-5p $(r=0.478, p<0.001)$, and miR-214-3p $(r=0.453$, $p<0.001)$ and negatively correlated with miR-1290-3p levels $(r=-0.397, p<0.001$; Figure 6A-E). Similar results were observed for correlations between proteinuria levels and TNF- $\alpha(r=0.686, p<0.001)$, miR-31-5p $(r=0.614, p<0.001)$, miR-155-5p $(r=0.618, p<0.001)$, miR-214-3p $(r=0.543, p<0.001)$, and miR-1290-3p $(r=-0.376, p<0.001$; Figure $6 \mathrm{~F}-\mathrm{J})$. Collectively, these results raise the possibility that increased miR-31-5p, miR-155-5p, and miR-214-3p levels are correlated with clinical characteristics of PE, probably via TNF- $\alpha$ /NF- $\mathrm{kB}$-responsive miR-31-5p/155-5p-mediated downregulation of eNOS

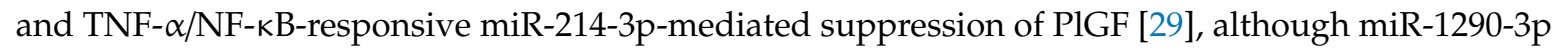
biogenesis and functions in PE are unknown. 
A

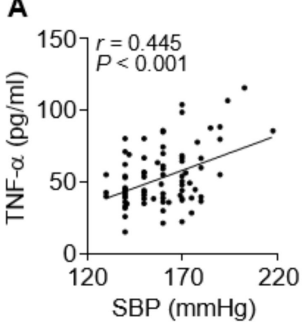

$\mathbf{F}$

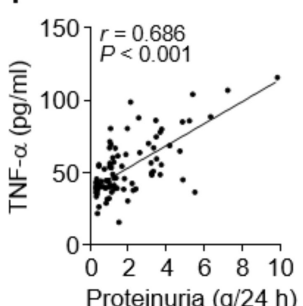

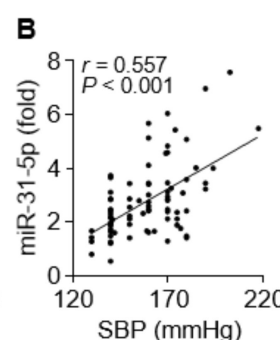

C
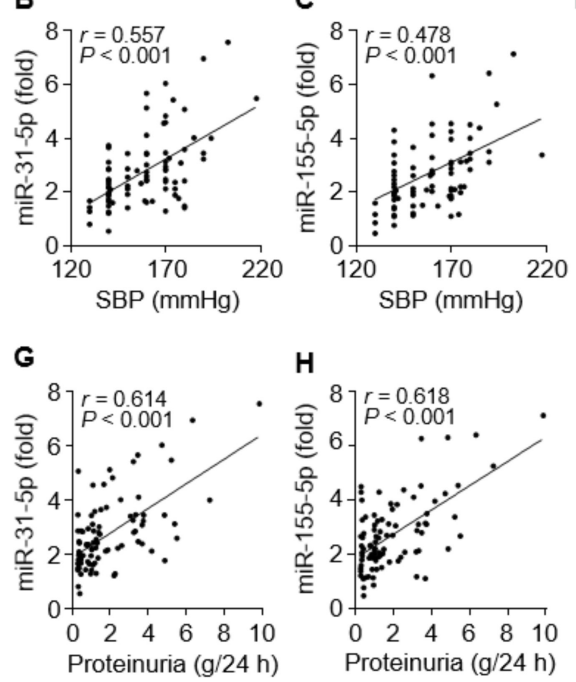

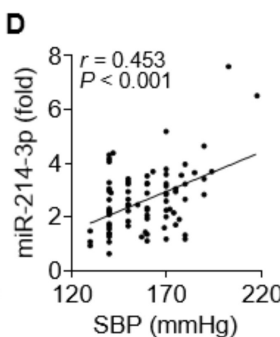

E

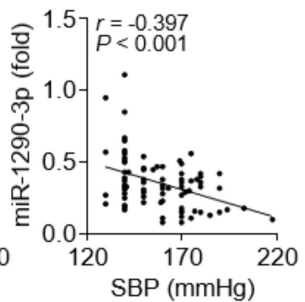

I

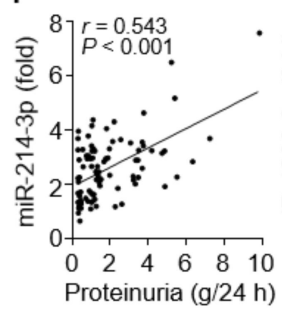

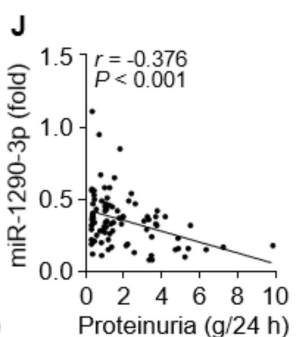

Figure 6. Correlation between miRNA levels and clinical symptoms in PE patients. (A-E) Correlation analysis between systolic blood pressure (SBP) and TNF- $\alpha$ or the level of each miRNA. (F-J) Correlation analysis between proteinuria and TNF- $\alpha$ or the level of each miRNA. $n=92$.

\subsection{The miRNAs are Useful Serum Factors as Diagnostic Biomarkers in PE}

To evaluate the diagnostic value of circulating TNF- $\alpha$, NOx, and cGMP for PE, ROC curve analysis was performed. A comparison of PE patients and normal pregnant subjects showed that serum levels of TNF- $\alpha$, NOx, and cGMP had the area under the ROC curve (AUC) of 0.917 (95\% CI 0.876-0.985), 0.811 (95\% CI $0.750-0.873)$, and 0.741 (95\% CI $0.655-0.826)$, with a sensitivity of $90.22 \%, 72.83 \%$, and $88.04 \%$ and specificity of $83.70 \%, 79.35 \%$, and $43.59 \%$, respectively (Figure $7 \mathrm{~A}-\mathrm{C}$ and Table 2). These results suggest that among these soluble factors, TNF- $\alpha$ has better diagnostic value than others in the sera of suspected patients with PE. TNF- $\alpha$ has been known to elicit endothelial dysfunction associated with hypertension through the downregulation of eNOS by upregulating NF- $k B-$ responsive miR-31-5p and miR-155-5p [15,16]. Thus, we next compared the diagnostic accuracy of the miRNAs between sera of PE patients and healthy controls using ROC curve analyses. Individual miR-31-5p, miR-155-5p, miR-214-3p, and miR-1290-3p had AUC values of 0.960 (95\% CI 0.931-0.990), 0.931 (95\% CI 0.895-0.967), 0.924 (95\% CI 0.887-0.962), and 0.957 (95\% CI $0.931-0.984)$, with a sensitivity of $95.65 \%, 89.13 \%, 90.22 \%$, and $94.57 \%$ and specificity of $92.39 \%, 88.04 \%, 79.35 \%$, and $84.78 \%$, respectively (Figure $7 \mathrm{D}-\mathrm{G}$ and Table 2). We further analyzed the synergistic diagnostic power by combination analysis among these miRNAs, except miR-1290-3p, since it was downregulated in the patients. Combinations of miR-31-5p and miR-155-5p, miR-31-5p, and miR-214-3p, and miR-155-5p and miR-214-3p yielded AUC values of 0.945 (95\% CI 0.922-0.968), 0.944 (95\% CI 0.921-0.967), and 0.929 (95\% CI 0.903-0.955), with a sensitivity of $90.76 \%, 93.48 \%$, and $86.96 \%$ and specificity of $90.76 \%, 85.33 \%$, and $84.24 \%$, respectively (Figure $7 \mathrm{H}-\mathrm{J}$ and Table 2). These results suggest that these individual miRNAs are potential biomarkers with greater than $90 \%$ diagnostic accuracy, which was not further increased by their combined analysis. 

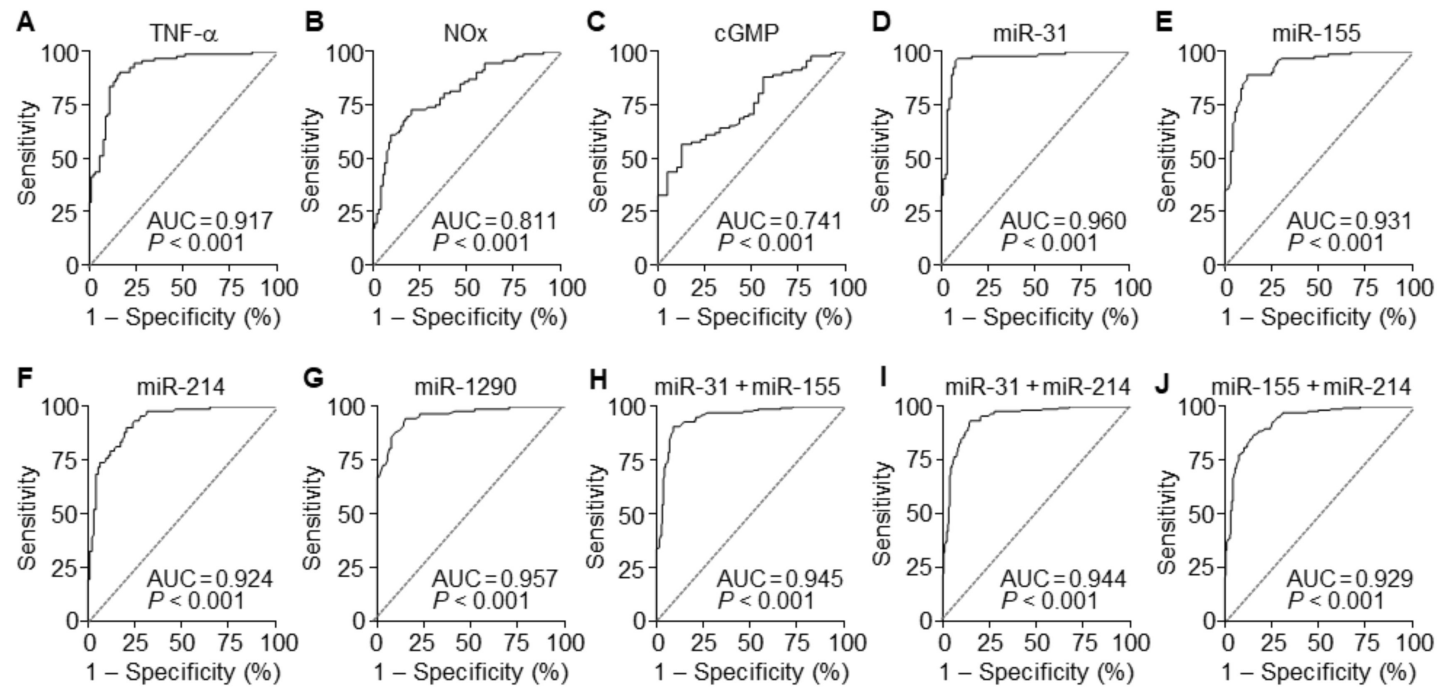

Figure 7. Diagnostic values of soluble factors and miRNAs. (A-D) ROC curve analysis was performed to evaluate the diagnostic power of TNF- $\alpha(\mathbf{A})$, NOx (B), and CGMP (C). (D-G) ROC curve analyses of miR-31-5p (D), miR-155-5p (E), miR-214-3p (F), and miR-1290-3p (G) in the discrimination of PE patients from healthy controls. (H-J) ROC curve analyses of the combination of miR-31-5p + miR-155-5p (H), miR-31-5p + miR-214-3p (I), and miR-155-5p + miR-214-3p (J). $n=$ total 184 participants (92 PE patients and 92 healthy controls) per soluble factor or miRNA.

Table 2. Diagnostic values of miRNAs and other factors between PE patients and healthy controls.

\begin{tabular}{lcccccc}
\hline Serum Factors & AUC & $\mathbf{9 5} \% \mathbf{C I}$ & Sensitivity & Specificity & Cut-off & $\boldsymbol{p}$-Value \\
\hline TNF- $\alpha$ & 0.917 & $0.876-0.958$ & 90.22 & 83.70 & 34.89 & $<0.001$ \\
NOx & 0.811 & $0.750-0.873$ & 72.83 & 79.35 & 44.59 & $<0.001$ \\
cGMP & 0.741 & $0.655-0.826$ & 88.04 & 43.59 & 31.77 & $<0.001$ \\
miR-31-5p & 0.960 & $0.931-0.990$ & 95.65 & 92.39 & 1.275 & $<0.001$ \\
miR-155-5p & 0.931 & $0.895-0.967$ & 89.13 & 88.04 & 1.365 & $<0.001$ \\
miR-214-3p & 0.924 & $0.887-0.962$ & 90.22 & 79.35 & 1.250 & $<0.001$ \\
miR-1290-3p & 0.957 & $0.931-0.984$ & 94.57 & 84.78 & 0.595 & $<0.001$ \\
miR-31-5p+miR-155-5p & 0.945 & $0.922-0.968$ & 90.76 & 90.76 & 1.365 & $<0.001$ \\
miR-31-5p+miR-214-3p & 0.944 & $0.921-0.967$ & 93.48 & 85.33 & 1.265 & $<0.001$ \\
miR-214-3p+miR-155-5p & 0.929 & $0.903-0.955$ & 86.96 & 84.24 & 1.355 & $<0.001$ \\
\hline
\end{tabular}

\subsection{The Ratios of miR-31-5p, miR-155-5p, and miR-214-3p to miR-1290-3p Improve Diagnostic Accuracy}

Since miR-1290-3p was downregulated in patients with PE, we next analyzed the diagnostic values using the ratios of upregulated miR-31-5p, miR-155-5p, and miR-214-3p to miR-1290-3p. As expected, the ratios of all three miRNAs to miR-1290-3p were significantly higher in PE patients than in healthy pregnant women (Figure 8A-C). ROC curve analysis using the ratios of miR-31-5p, miR-155-5p, and miR-214-3p to miR-1290-3p yielded AUC values of 0.995 (95\% CI 0.989-1.000), 0.990 (95\% CI $0.981-1.000)$, and 0.986 (95\% CI $0.973-0.999)$, with a sensitivity of $95.65 \%, 93.48 \%$, and $94.57 \%$ and specificity of $97.83 \%, 97.83 \%$, and $96.74 \%$, respectively (Figure $8 \mathrm{D}-\mathrm{G}$ ). These results suggest that these ratios have better potential diagnostic power with over $95 \%$ accuracy for PE than miRNAs individually or in combination. 
A

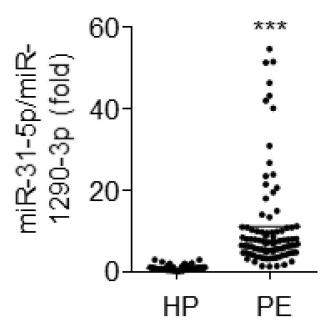

E

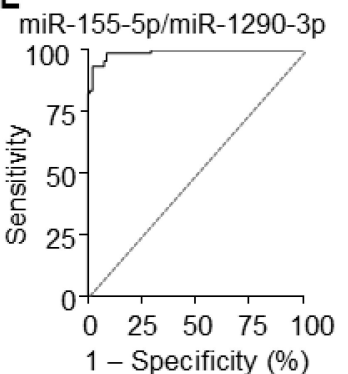

B

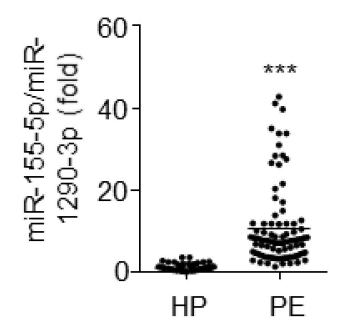

$\mathbf{F}$

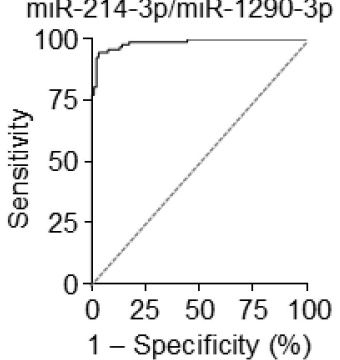

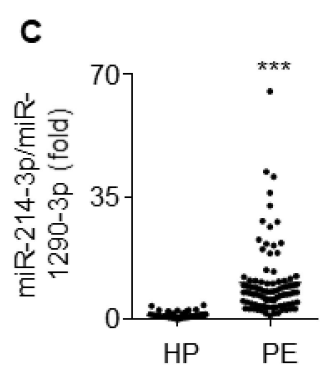

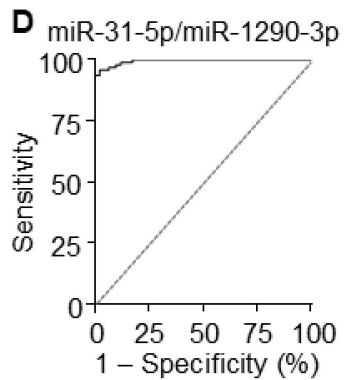

G

\begin{tabular}{lccc}
\hline & $\begin{array}{c}\text { miR-31-5p/ } \\
\text { miR-1290-3p }\end{array}$ & $\begin{array}{c}\text { miR-155-5p/ } / \\
\text { miR-1290-3p }\end{array}$ & $\begin{array}{c}\text { miR-214-3p/ } \\
\text { miR-1290-3p }\end{array}$ \\
\hline AUC & 0.995 & 0.990 & 0.986 \\
$95 \%$ Cl & $0.989-1.000$ & $0.981-1.000$ & $0.973-0.999$ \\
Sensitivity & 95.65 & 93.48 & 94.57 \\
Specificity & 97.83 & 97.83 & 96.74 \\
Cut-off & 2.514 & 2.767 & 2.615 \\
P value & $<0.001$ & $<0.001$ & $<0.001$ \\
\hline
\end{tabular}

Figure 8. Diagnostic values for the ratios of miR-31-5p, miR-155-5p, and miR-214-3p levels to miR-1290-3p level. (A-C) Comparative ratios of miR-31-5p (A), miR-155-5p (B), and miR-214-3p levels (C) to miR-1290-3p level in PE patients (PE) and healthy pregnant women (HP). $n=92$ per group, *** $p<0.001$. (D-F) ROC curve analysis of miR-31-5p/miR-1290-3p ratio (D), miR-155-5p/miR-1290-3p ratio (E), miR-214-3p/miR-1290-3p (F) in the discrimination of PE patients from healthy pregnant women. $n=$ total 184 participants (92 PE patients and 92 healthy controls) per miRNA. (G) Summary of the diagnostic values of the miR-31-5p/miR-1290-3p ratio, miR-155-5p/miR-1290-3p ratio, and $\mathrm{miR}-214-3 \mathrm{p} / \mathrm{miR}-1290-3 \mathrm{p}$ ratio.

\section{Discussion}

It is well-known that placental lesions and uteroplacental vascular insufficiency cause an imbalanced angiogenic state, such as high sFlt1 and sEng levels and low PlGF levels, which are associated with the pathogenesis of PE [6,8]. Accumulating evidence has demonstrated that the sFlt-1/PlGF ratio is significantly increased in maternal blood in the early stage of the clinical development of $\mathrm{PE}$ and is considered a diagnostic biomarker $[9,10]$. This suggests that circulating levels of sFlt-1 and PlGF can be used as pathogenic risk factors and diagnostic and prognostic biomarkers of PE. Unfortunately, pregnant women with a high sFlt-1/PlGF ratio do not always develop hypertension and proteinuria [11,12]. Therefore, new accurate biomarkers directly linked to the clinical symptoms of PE are needed to improve their predictive values.

$P E$ is a pregnancy-specific vascular disease that is also considered an inflammatory disorder caused by the elevation of circulating proinflammatory cytokines in the patients [30-32]. We and others have previously demonstrated that serum levels of inflammatory cytokines, including TNF- $\alpha$, which induces vasoconstriction and hypertension, are significantly elevated in the patients [15-19,33]. Infusion of TNF- $\alpha$ into pregnant rodents and nonhuman primates induces PE-like syndrome [24,34], implying the critical involvement of TNF- $\alpha$ in the pathogenesis of PE. In this study, we also found a potential role of TNF- $\alpha$ in the pathogenesis of PE by confirming a correlation between TNF- $\alpha$ levels and the sFlt-1/PlGF ratio or clinical symptoms. In addition, circulating miR-31-5p, miR-155-5p, and miR-214-3p levels were increased in PE patients and highly correlated with TNF- $\alpha$ levels, the sFlt-1/PlGF ratio, and clinical symptoms. In contrast, miR-1290-3p levels were decreased and inversely correlated with clinical symptoms, although miR-1290-3p expression was not altered by TNF- $\alpha$ and NF- $\mathrm{kB}$ activation. Collectively, our data suggest that these miRNAs are promising diagnostic or prognostic biomarkers for PE. However, to utilise the miRNAs as predictive factors of PE, further studies are needed for the 
prospective analysis of the predictive and correlative values between the circulating mRNA levels before the onset of symptoms and late-onset PE.

The eNOS/NO pathway plays a crucial role in vasorelaxation, angiogenesis, and vascular remodeling. Thus, inhibition or knockdown of eNOS elicits PE-like syndromes, such as hypertension and proteinuria, in rats and mice $[25,35,36]$. This suggests that impairment of the eNOS/NO/cGMP axis causes endothelial dysfunction, which is directly associated with the pathogenesis of PE. More recent studies showed that elevated TNF- $\alpha$ in PE is responsible for the NF- $\mathrm{KB}$-mediated biogenesis of miR-31-5p and miR-155-5p and subsequent inhibition of the eNOS/NO axis in cultured human endothelial cells, resulting in the impairment of vascular relaxation and trophoblast invasion $[15,16]$. Similarly, our data demonstrated a strong correlation between TNF- $\alpha$ levels and miR-31-5p or miR-155-5p level and a concomitant decrease in eNOS expression in PE subjects. We also directly demonstrated that TNF- $\alpha$ inhibits eNOS expression in HUVECs by NF- $\kappa B-d e p e n d e n t$ biogenesis of miR-31-5p and miR-155-5p. These findings suggest that preeclamptic hypertension can be caused by the downregulation of the eNOS/NO axis via NF- $\mathrm{kB}-$ mediated biogenesis of miR-31-5p and miR-155-5p.

NF-kB-regulated miR-155-5p downregulates the NO-dependent sGC/cGMP/PKG axis in vascular smooth muscle cells (vSMCs) [18,19], leading to additional vasocontraction and hypertension. Unexpectedly, we found that serum NOx and cGMP levels were elevated in PE, although their levels have been shown to be equivocally altered, i.e., decreased, increased, or remained unchanged, in the blood of PE patients [37]. These phenomena might be associated with the differential expression of eNOS and iNOS via the activation of NF- $\mathrm{KB}$ in response to inflammatory cytokines. Indeed, NF- $\mathrm{KB}$ is significantly activated in the placenta in PE patients [38]. NF- $\mathrm{KB}$ has dual functions in pathophysiological NO production, through the transcriptional induction of iNOS in various types of cells, including vSMCs, hepatocytes, and macrophages [39], and the post-translational downregulation of eNOS in endothelial cells via the biogenesis of miR-31-5p and miR-155-5p [16,17]. In general, iNOS is able to synthesize high (micromolar) amounts of NO for many hours or even days, whereas eNOS produces lower (picomolar) and transient levels of NO. Therefore, increased NOx/cGMP levels in PE are thought to be due to the significant induction of iNOS, although eNOS was downregulated. Because NO synthesized by eNOS and iNOS has different biological functions, such as vascular functions and immune regulation, respectively [39], the decreased eNOS/NO pathway is responsible for hypertension and proteinuria in PE, while the elevated iNOS levels stimulate immune activation and tissue damage. Based on all these findings, increased NOx/cGMP levels are due to NF- $\mathrm{kB}$-dependent iNOS induction and are unlikely to be linked to the regulation of vascular function. Thus, NOx and cGMP levels are not better diagnostic biomarkers for PE than miR-31-5p and miR-155-5p levels, which are associated with vascular dysfunction by downregulating eNOS, sGC, and PKG in the endothelial cells and vSMCs of PE patients.

Besides miR-31-5p and miR-155-5p, we also identified that miR-214-3p was significantly elevated in the sera of the patients and upregulated in trophoblasts stimulated with TNF- $\alpha$. miR-214-3p is located on the opposite strand of an intron of dynamin 3 [40], and its expression is modulated by NF-kB (Figure 5) and hypoxia-inducible factor (HIF)-1 $\alpha$ [41]. Given the evidence that inflammation and hypoxia are crucial risk factors for PE [4,32], miR-214-3p is expected to be increased in women with PE. Although miR-214-3p has been shown to be equivocally linked to PE, with microarray data showing its downregulation and qRT-PCR data indicating its upregulation [41], we demonstrated that miR-214-3p was upregulated in an NF-kB-dependent manner in the human trophoblast cell line HTR-8/SVneo treated with TNF- $\alpha$. Consistent with a previous study [29], our data showed that NF-kB-dependent miR-214-3p biogenesis is responsible for TNF- $\alpha$-mediated suppression of PlGF production, suggesting that miR-214-3p expression precedes the downregulation of PlGF and is an earlier and better diagnostic biomarker of PE than PIGF. We also found that there is a strong inverse correlation between circulating levels of miR-214-3p and PlGF in PE patients. PIGF is highly expressed in the placenta in all gestational stages and promotes trophoblast invasion into the decidua, as well as spiral artery remodeling. Therefore, increased miR-214-3p levels can cause preeclamptic characteristics 
via PIGF downregulation and defects in spiral artery remodeling, thereby representing a reliable biomarker for the early diagnosis of PE.

miR-1290-3p is upregulated in tumor stem cells [42] or downregulated during neuronal differentiation [43], suggesting that it somehow participates in cell division and cellular differentiation in the embryo. A recent study showed that miR-1290-3p was highly upregulated in the endometrium on Day 3 of the bovine estrous cycle, followed by rapid downregulation [44], suggesting that its level is regulated in an ovarian hormone-responsive manner and that it plays an important role in endometrial contribution to the implantation and survival of embryos. In fact, miR-1290-3p expression is downregulated in estrogen receptor $\alpha$-positive breast cancer tumors [45], indicating that estrogens negatively regulate miR-1290-3p. Notably, estrogen concentrations were elevated in PE versus healthy controls $[27,46,47]$. This suggests that miR-1290-3p is downregulated in PE, consistent with our present findings. Although its expression regulation and target genes are largely unknown in PE, miR-1290-3p can be used as a downregulated biomarker of PE, similar to PlGF.

The pathogenesis of PE occurs as a consequence of interactions among multiple factors, including hypoxia, the immune system, the hormonal system, and oxidative stress [48]. Thus, a single factor is not sufficient to explain the pathogenic mechanism or determine the diagnosis of PE. The strengths of this study include the identification of multiple mechanism-based miRNAs, including inflammation-responsive miR-31-5p and miR-155-5p, and NF-kB/HIF- $\alpha$-dependent miR-214-3p and miR-1290-3p (Figure 9). Their serum levels were highly correlated with the sFlt-1/PIGF ratio and clinical symptoms and had high diagnostic accuracy as demonstrated by ROC value analysis. However, miR-155-5p has been shown to be elevated in several pathogenic conditions, such as cancer, inflammatory disorders, obesity, and diabetes [49,50], suggesting that miR-155-5p is useful, but not ideal, for the diagnosis for PE. The other miRNAs are considered more specific to PE than miR-155-5p because they are expressed to a limited extent in few other pathological conditions. More notably, all the miRNAs, except miR-1290-3p, the function of which is unknown, are considered risk factors for the development of $\mathrm{PE}$ and are thus useful as mechanism-based biomarkers for diagnosing PE. Because miR-1290-3p, considered an inflammation/NF-kB-insensitive and estrogen-responsive biomarker, was downregulated in PE patients, the ratios of miR-31-5p, miR-155-5p, or miR-214-3p to miR-1290-3p may be clinically useful as effective diagnostic determinants for $\mathrm{PE}$, as shown by the diagnostic value of the sFlt1/PIGF ratio. Using the current analytical techniques with qPCR and silver nanocluster DNA probes [51], these miRNAs can be analyzed quickly in a small volume of blood, representing a test that could aid the risk stratification of women with suspected PE.

In conclusion, we identified that the serum levels of several biomarkers were significantly elevated in patients with PE. Among them, NF-KB-responsive miR-31-5p, miR-155-5p, and miR-214-3p could be used as novel mechanism-based diagnostic biomarkers and therapeutic targets for PE (Figure 9). Furthermore, the ratios of those miRNAs to miR-1290-3p, which was reduced in PE, showed greater diagnostic power than that of their individual miRNA, providing evidence that these ratios might be of potential value in the diagnosis and prognosis of women with suspected PE, although the case numbers are still too low to make sufficient differentiation. 


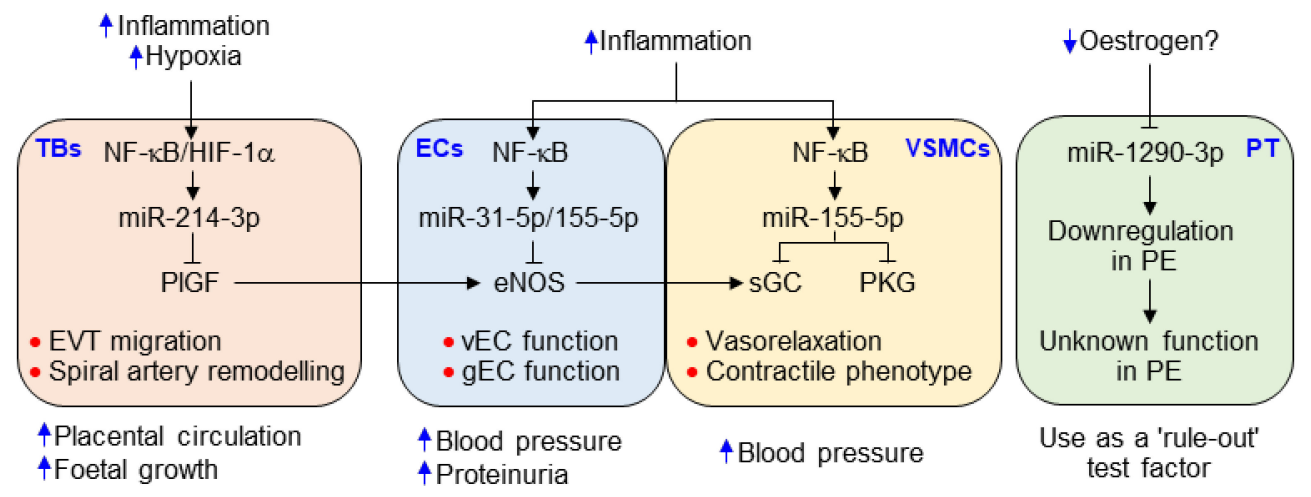

Figure 9. Possible roles of the identified miRNAs in the pathogenesis of PE. Hypoxia, inflammation, and decreased estrogen levels caused by inappropriate implantation. Inflammation and hypoxia increase the biogenesis of miR-31-5p, miR-155-5p, and miR-214-3p in endothelial cells (ECs), vSMCs, and the trophoblast (TB) via activation of NF- $\mathrm{B}$ B and HIF-1 $\alpha$. They inhibit the expression of eNOS in ECs [16-18], sGC and PKG [19,20] in vSMCs, and PIGF in the TB (Figure 5), resulting in the impairment of vasorelaxation and TB invasion, which cause hypertension, proteinuria, and spiral artery remodeling. Meanwhile, reduced estrogen levels downregulate miR-1290-3p in placental tissue (PT); the function of miR-1290-3p, however, has not been identified in the development of PE. Nevertheless, decreased miR-1290-3p level is considered a "rule-out" test factor, like the reduced PlGF level that is used as a critical factor to discriminate against women with suspected PE from healthy pregnant women.

Author Contributions: Y.-M.K. designed and conceptualized the research. S.K., M.P., J.-Y.K., and T.K. performed the experimental work; analyzed the data; and wrote the manuscript. J.Y.H. provided clinical specimens. M.P. and S.R. statistically analyzed the data. K.-S.H., M.-H.W., and Y.-G.K. advised on the experimental design and the manuscript. Y.-M.K. directed the overall project. All authors read and approved the final manuscript.

Funding: This work was supported by National Research Foundation of Korea (NRF) grants funded by the Korea Government (2016M3A9B6903103 and 2017R1A2B3004565).

Conflicts of Interest: We declare no conflicting interests.

\section{References}

1. Steegers, E.A.; von Dadelszen, P.; Duvekot, J.J.; Pijnenborg, R. Preeclampsia. Lancet 2010, 376, 631-644. [CrossRef]

2. Duley, L. The global impact of pre-eclampsia and eclampsia. Semin Perinatol. 2009, 33, 130-137. [CrossRef] [PubMed]

3. Berg, C.J.; MacKay, A.P.; Qin, C.; Callaghan, W.M. Overview of maternal morbidity during hospitalization for labor and delivery in the united states: 1993-1997 and 2001-2005. Obstet. Gynecol. 2009, 113, 1075-1081. [CrossRef]

4. Alice, W.; Sarosh, R.S.; Ananth, K. Preeclampsia: The role of angiogenic factors in its pathogenesis. Physiology 2009, 24, 147-158.

5. Thangaratinam, S.; Coomarasamy, A.; O’Mahony, F.; Sharp, S.; Zamora, J.; Khan, K.S.; Ismail, K.M.K. Estimation of proteinuria as a predictor of complications of pre-eclampsia: A systematic review. BMC Med. 2009, 7, 10. [CrossRef] [PubMed]

6. Zeisler, H.; Llurba, E.; Chantraine, F.J.; Vatish, M.; Staff, A.C.; Sennström, M.; Olovsson, M.; Brennecke, S.P.; Stepan, H.; Allegranza, D.; et al. Soluble fms-like tyrosine kinase-1 to placental growth factor ratio: Ruling out pre-eclampsia for up to 4 weeks and value of retesting. Ultrasound Obstet. Gynecol. 2019, 53, 367-375. [CrossRef]

7. Chaiworapongsa, T.; Romero, R.; Korzeniewski, S.J.; Cortez, J.M.; Pappas, A.; Tarca, A.L.; Chaemsaithong, P.; Dong, Z.; Yeo, L.; Hassan, S.S. Plasma concentrations of angiogenic/anti-angiogenic factors have prognostic value in women presenting with suspected preeclampsia to the obstetrical triage area: A prospective study. J. Matern. Fetal. Neonatal. Med. 2014, 27, 132-144. [CrossRef] [PubMed] 
8. Levine, R.J.; Maynard, S.E.; Qian, C.; Lim, K.H.; England, L.J.; Yu, K.F.; Schisterman, E.F.; Thadhani, R.; Sachs, B.P.; Epstein, F.H.; et al. Circulating angiogenic factors and the risk of preeclampsia. N. Engl. J. Med. 2004, 350, 672-683. [CrossRef]

9. Verlohren, S.; Galindo, A.; Schlembach, D.; Zeisler, H.; Herraiz, I.; Moertl, M.G.; Pape, J.; Dudenhausen, J.W.; Denk, B.; Stepan, H. An automated method for the determination of the sFlt-1/PIGF ratio in the assessment of preeclampsia. Am. J. Obstet. Gynecol. 2010, 202, 161.e1-161.e11. [CrossRef]

10. Sunderji, S.; Gaziano, E.; Wothe, D.; Rogers, L.C.; Sibai, B.; Karumanchi, S.A.; Hodges-Savola, C. Automated assays for sVEGF R1 and PIGF as an aid in the diagnosis of preterm preeclampsia: A prospective clinical study. Am. J. Obstet. Gynecol. 2010, 202, 40.e1-40.e7. [CrossRef]

11. Herraiz, I.; Llurba, E.; Verlohren, S.; Galindo, A. Spanish Group for the Study of Angiogenic Markers in Preeclampsia. Update on the diagnosis and prognosis of preeclampsia with the aid of the sFlt-1/PlGF ratio in singleton pregnancies. Fetal Diagn. Ther. 2018, 43, 81-89. [CrossRef] [PubMed]

12. Pant, V.; Yadav, B.K.; Sharma, J. A cross sectional study to assess the sFlt-1:PlGF ratio in pregnant women with and without preeclampsia. BMC Pregnancy Childbirth 2019, 19, 266.

13. Munaut, C; Tebache, L; Blacher, S; Noël, A; Nisolle, M; Chantraine, F. Dysregulated circulating miRNAs in preeclampsia. Biomed. Rep. 2016, 5, 686-692. [CrossRef] [PubMed]

14. Hornakova, A; Kolkova, Z; Holubekova, V; Loderer, D; Lasabova, Z; Biringer, K; Halasova, E. Diagnostic Potential of MicroRNAs as Biomarkers in the Detection of Preeclampsia. Genet. Test. Mol. Biomarkers 2020, 24, 321-327. [CrossRef] [PubMed]

15. Kim, J.; Lee, K.S.; Kim, J.H.; Lee, D.K.; Park, M.; Choi, S.; Park, W.; Kim, S.; Choi, Y.K.; Hwang, J.Y.; et al. Aspirin prevents TNF- $\alpha$-induced endothelial cell dysfunction by regulating the NF- $\mathrm{B}$-dependent miR-155/eNOS pathway: Role of a miR-155/eNOS axis in preeclampsia. Free Radic. Biol. Med. 2017, 104, 185-198. [CrossRef] [PubMed]

16. Kim, S.; Lee, K.S.; Choi, S.; Kim, J.; Lee, D.K.; Park, M.; Park, W.; Kim, T.H.; Hwang, J.Y.; Won, M.H.; et al. NF-kB-responsive miRNA-31-5p elicits endothelial dysfunction associated with preeclampsia via down-regulation of endothelial nitric-oxide synthase. J. Biol. Chem. 2018, 293, 18989-19000. [CrossRef]

17. Lee, K.S.; Kim, J.; Kwak, S.N.; Lee, K.S.; Lee, D.K.; Ha, K.S.; Won, M.H.; Jeoung, D.; Lee, H.; Kwon, Y.G.; et al. Functional role of NF- $\mathrm{KB}$ in expression of human endothelial nitric oxide synthase. Biochem. Biophys. Res. Commun. 2014, 448, 101-107. [CrossRef]

18. Park, M.; Choi, S.; Kim, S.; Kim, J.; Lee, D.K.; Park, W.; Kim, T.; Jung, J.; Hwang, J.Y.; Won, M.H.; et al. NF-kB-responsive miR-155 induces functional impairment of vascular smooth muscle cells by downregulating soluble guanylyl cyclase. Exp. Mol. Med. 2019, 51,1-12. [CrossRef]

19. Choi, S.; Park, M.; Kim, J.; Park, W.; Kim, S.; Lee, D.K.; Hwang, J.Y.; Choe, J.; Won, M.H.; Ryoo, S.; et al. TNF- $\alpha$ elicits phenotypic and functional alterations of vascular smooth muscle cells by miR-155-5p-dependent down-regulation of cGMP-dependent kinase 1. J. Biol. Chem. 2018, 293, 14812-14822. [CrossRef]

20. Brown, M.A.; Magee, L.A.; Kenny, L.C.; Karumanchi, S.A.; McCarthy, F.P.; Saito, S.; Hall, D.R.; Warren, C.E.; Adoyi, G.; Ishaku, S. Hypertensive disorders of pregnancy: ISSHP Classification, diagnosis, and management recommendations for international practice. Hypertension 2018, 72, 24-43. [CrossRef]

21. Salzman, A.; Denenberg, A.G.; Ueta, I.; O'Connor, M.; Linn, S.C.; Szabó, C. Induction and activity of nitric oxide synthase in cultured human intestinal epithelial monolayers. Am. J. Physiol. 1996, 270, G565-G573. [CrossRef] [PubMed]

22. Breslau, N.; Paneth, N.S.; Lucia, V.C. The lingering academic deficits of low birth weight children. Pediatrics 2004, 114, 1035-1040. [CrossRef] [PubMed]

23. Poon, L.C.; Tan, M.Y.; Yerlikaya, G.; Syngelaki, A.; Nicolaides, K.H. Birth weight in live births and stillbirths. Ultrasound Obstet. Gynecol. 2016, 48, 602-606. [CrossRef] [PubMed]

24. Verlohren, S.; Stepan, H.; Dechend, R. Angiogenic growth factors in the diagnosis and prediction of pre-eclampsia. Clin. Sci. (Lond) 2012, 122, 43-52. [CrossRef]

25. Li, F.; Hagaman, J.R.; Kim, H.S.; Maeda, N.; Jennette, J.C.; Faber, J.E.; Karumanchi, S.A.; Smithies, O.; Takahashi, N. eNOS deficiency acts through endothelin to aggravate sFlt-1-induced pre-eclampsia-like phenotype. J. Am. Soc. Nephrol. 2012, 23, 652-660. [CrossRef]

26. Billiar, T.R.; Curran, R.D.; Harbrecht, B.G.; Stadler, J.; Williams, D.L.; Ochoa, J.B.; Di Silvio, M.; Simmons, R.L.; Murray, S.A. Association between synthesis and release of cGMP and nitric oxide biosynthesis by hepatocytes. Am. J. Physiol. 1992, 262, C1077-C1082. [CrossRef] 
27. Cantonwine, D.E.; McElrath, T.F.; Trabert, B.; Xu, X.; Sampson, J.; Roberts, J.M.; Hoover, R.N.; Troisi, R. Estrogen metabolism pathways in preeclampsia and normal pregnancy. Steroids 2019, 144, 8-14. [CrossRef]

28. Chau, K.; Bobek, G.; Xu, B.; Stait-Gardner, T.; Price, W.; Hennessy, A.; Makris, A. Effect of placental growth factor in models of experimental pre-eclampsia and trophoblast invasion. Clin. Exp. Pharmacol. Physiol. 2020, 47, 49-59. [CrossRef]

29. Gonsalves, C.S.; Li, C.; Mpollo, M.S.E.M.; Pullarkat, V.; Malik, P.; Tahara, S.M.; Kalra, V.K. Erythropoietin-mediated expression of placenta growth factor is regulated via activation of hypoxia-inducible factor- $1 \alpha$ and post-transcriptionally by miR-214 in sickle cell disease. Biochem. J. 2015, 468, 409-423. [CrossRef]

30. Taylor, B.D.; Ness, R.B.; Klebanoff, M.A.; Zoh, R.; Bass, D.; Hougaard, D.M.; Skogstrand, K.; Haggerty, C.L. First and second trimester immune biomarkers in preeclamptic and normotensive women. Pregnancy Hypertens. 2016, 6, 388-393. [CrossRef]

31. Catarino, C.; Santos-Silva, A.; Belo, L.; Rocha-Pereira, P.; Rocha, S.; Patrício, B.; Quintanilha, A.; Rebelo, I. Inflammatory disturbances in preeclampsia: Relationship between maternal and umbilical cord blood. J. Pregnancy 2012, 2012, 684384. [CrossRef] [PubMed]

32. Harmon, A.C.; Cornelius, D.C.; Amaral, L.M.; Faulkner, J.L.; Cunningham, M.W., Jr.; Wallace, K.; LaMarca, B. The role of inflammation in the pathology of preeclampsia. Clin. Sci. (Lond) 2016, 130, 409-419. [CrossRef] [PubMed]

33. Alexander, B.T.; Cockrell, K.L.; Massey, M.B.; Bennett, W.A.; Granger, J.P. Tumor necrosis factor- $\alpha$-induced hypertension in pregnant rats results in decreased renal neuronal nitric oxide synthase expression. Am. J. Hypertens. 2002, 15, 170-175. [CrossRef]

34. Sunderland, N.S.; Thomson, S.E.; Heffernan, S.J.; Lim, S.; Thompson, J.; Ogle, R.; McKenzie, P.; Kirwan, P.J.; Makris, A.; Hennessy, A. Tumor necrosis factor $\alpha$ induces a model of preeclampsia in pregnant baboons (Papio hamadryas). Cytokine 2011, 56, 192-199. [CrossRef]

35. Baylis, C.; Mitruka, B.; Deng, A. Chronic blockade of nitric oxide synthesis in the rat produces systemic hypertension and glomerular damage, J. Clin. Invest. 1992, 90, 278-281. [CrossRef]

36. Huang, P.L.; Huang, Z.; Mashimo, H.; Bloch, K.D.; Moskowitz, M.A.; Bevan, J.A.; Fishman, M.C. Hypertension in mice lacking the gene for endothelial nitric oxide synthase. Nature 1995, 377, 239-242. [CrossRef]

37. López-Jaramillo, P.; Arenas, W.D.; García, R.G.; Rincon, M.Y.; López, M. The role of the L-arginine-nitric oxide pathway in preeclampsia. Ther. Adv. Cardiovasc. Dis. 2008, 2, 261-275. [CrossRef]

38. Vaughan, J.E.; Walsh, S.W. Activation of NF-kB in placentas of women with preeclampsia. Hypertens. Pregnancy 2012, 31, 243-251. [CrossRef]

39. Förstermann, U.; Sessa, W.C. Nitric oxide synthases: Regulation and function. Eur. Heart J. 2012, 33, 829-837. [CrossRef]

40. Watanabe, T.; Sato, T.; Amano, T.; Kawamura, Y.; Kawamura, N.; Kawaguchi, H.; Yamashita, N.; Kurihara, H.; Nakaoka, T. Dnm3os, a non-coding RNA, is required for normal growth and skeletal development in mice. Dev. Dyn. 2008, 237, 3738-3748. [CrossRef]

41. Xu, P.; Zhao, Y.; Liu, M.; Wang, Y.; Wang, H.; Li, Y.X.; Zhu, X.; Yao, Y.; Wang, H.; Qiao, J.; et al. Variations of microRNAs in human placentas and plasma from preeclamptic pregnancy. Hypertension 2014, 63, 1276-1284. [CrossRef] [PubMed]

42. Zhang, W.C.; Chin, T.M.; Yang, H.; Nga, M.E.; Lunny, D.P.; Lim, E.K.H.; Sun, L.L.; Pang, Y.H.; Leow, Y.N.; Malusay, S.R.Y.; et al. Tumour-initiating cell-specific miR-1246 and miR-1290 expression converge to promote non-small cell lung cancer progression. Nat. Commun. 2016, 7, 11702. [CrossRef] [PubMed]

43. Moore, D.; Meays, B.M.; Madduri, L.S.V.; Shahjin, F.; Chand, S.; Niu, M.; Albahrani, A.; Guda, C.; Pendyala, G.; Fox, S.H.; et al. Downregulation of an evolutionary young miR-1290 in an iPSC-derived neural stem cell model of autism spectrum disorder. Stem Cells Int. 2019, 2019, 8710180. [CrossRef] [PubMed]

44. Ponsuksili, S.; Tesfaye, D.; Schellander, K.; Hoelker, M.; Hadlich, F.; Schwerin, M.; Wimmers, K. Differential expression of miRNAs and their target mRNAs in endometria prior to maternal recognition of pregnancy associates with endometrial receptivity for in vivo- and in vitro-produced bovine embryos. Biol. Reprod. 2014, 91, 135. [CrossRef] [PubMed]

45. Endo, Y.; Yamashita, H.; Takahashi, S.; Sato, S.; Yoshimoto, N.; Asano, T.; Hato, Y.; Dong, Y.; Fujii, Y.; Toyama, T. Immunohistochemical determination of the miR-1290 target arylamine $\mathrm{N}$-acetyltransferase 1 (NAT1) as a prognostic biomarker in breast cancer. BMC Cancer 2014, 4, 990. [CrossRef] 
46. Troisi, R.; Potischman, N.; Roberts, J.M.; Ness, R.; Crombleholme, W.; Lykins, D.; Siiteri, P.; Hoover, R.N. Maternal serum oestrogen and androgen concentrations in preeclamptic and uncomplicated pregnancies. Int. J. Epidemiol. 2003, 32, 455-460. [CrossRef]

47. Atamer, Y.; Erden, A.C.; Demir, B.; Koçyigit, Y.; Atamer, A. The relationship between plasma levels of leptin and androgen in healthy and preeclamptic pregnant women. Acta. Obstet. Gynecol. Scand. 2004, 83, 425-430. [CrossRef]

48. Tenório, M.B.; Ferreira, R.C.; Moura, F.A.; Bueno, N.B.; de Oliveira, A.C.M.; Goulart, M.O.F. Cross-Talk between Oxidative Stress and Inflammation in Preeclampsia. Oxid. Med. Cell Longev. 2019, 2019, 8238727. [CrossRef]

49. Hu, S.; Zhu, W.; Zhang, L.F.; Pei, M.; Liu, M.F. MicroRNA-155 broadly orchestrates inflammation-induced changes of microRNA expression in breast cancer. Cell Res. 2014, 24, 254-257. [CrossRef]

50. Gaudet, A.D.; Fonken, L.K.; Gushchina, L.V.; Aubrecht, T.G.; Maurya, S.K.; Periasamy, M.; Nelson, R.J.; Popovich, P.G. miR-155 deletion in female mice prevents diet-induced obesity. Sci. Rep. 2016, 6, 22862. [CrossRef]

51. Yang, S.W.; Vosch, T. Rapid detection of microRNA by a silver nanocluster DNA probe. Anal. Chem. 2011, 83, 6935-6939. [CrossRef] [PubMed]

(C) 2020 by the authors. Licensee MDPI, Basel, Switzerland. This article is an open access article distributed under the terms and conditions of the Creative Commons Attribution (CC BY) license (http://creativecommons.org/licenses/by/4.0/). 